Disponível em:

http://editora.unoesc.edu.br/index.php/race

Race, Joaçaba, v. 15, n. 1, p. 115-136, jan./abr. 2016

\title{
SENSIBILIDADE DAS POLÍTICAS MONETÁRIA, FISCAL E CAMBIAL NO COMBATE À INFLAÇÃO NO BRASIL
}

\section{Sensitivity of monetary, fiscal and exchange rate policies to fight inflation in Brazil}

\author{
Cássio Henrique Garcia Costa \\ E-mail: cassionep@yahoo.com.br \\ Mestre e doutorando em Administração pela Universidade de Lavras; Professor no \\ Instituto Federal do Sul de Minas.
}

Renato Silvério Campos

E-mail: renatocampos.ufla@gmail.com

Doutor em Economia pela Universidade Federal de Minas Gerais; Mestre em Economia pela Universidade de São Paulo; Professor efetivo do Departamento de Administração e Economia da Universidade Federal de Lavras.

Luiz Gonzaga de Castro Júnior

E-mail: gonzaga.ufla@gmail.com

Doutor em Economia Aplicada pela Universidade de São Paulo; Mestre em Administração pela Universidade Federal de Lavras; Professor da Universidade Federal de Lavras.

Endereço para correspondência: Avenida Doutor Sylvio Menicucci, 1001, Kennedy, 37200-000, Lavras, Minas Gerais, Brasil.

Artigo recebido em 01 de julho de 2015. Aceito em 11 de dezembro de 2015. 


\title{
Resumo
}

A atual forma de condução da política econômica brasileira tem como principal objetivo o controle inflacionário, sendo a taxa de juros o principal instrumento da política monetária utilizado pelo Banco Central para estabilizar a inflação em longo prazo. Diversos estudiosos têm debatido e investigado a eficácia da política monetária brasileira, seguindo a premissa de que aumentos na taxa Selic não seriam a forma mais eficaz de combate à inflação. Com o presente trabalho, visou-se determinar a sensibilidade das políticas fiscal, monetária e cambial no combate à inflação no Brasil, investigando empiricamente se a política monetária tem realmente o maior impacto no controle da inflação em longo prazo. Para isso, foi estimado um modelo de Vetores Correção de Erros (VEC). De acordo com os resultados,as principais variáveis que impactam a inflação em longo prazo são a dívida interna do setor público e o agerado monetário (M4). Também é alta a sensibilidade-câmbio da inflação. O Índice de Preços ao Consumidor Amplo (IPCA) se mostrou pouco sensível em longo prazo a alterações na taxa Selic. Apesar de se apresentar como o principal instrumento de política na condução do regime de metas da inflação, alterações na taxa de juros não têm sido determinantes em longo prazo no controle inflacionário.

Palavras-chave: Sensibilidade. Inflação. Políticas. Brasil.

\section{Sensitivity of monetary, fiscal and exchange rate policies to fight inflation in Brazil}

\begin{abstract}
The current form of conducting the Brazilian economic policy has as main objective the inflation control, and the interest rate the main instrument of monetary policy used by the Central Bank to stabilize inflation in the long run. Several researchers have debated and investigated the effectiveness of the Brazilian monetary policy, following the premise that increases in the Selic rate would not be the most effective way to fight inflation. This study aims to determine the sensitivity of fiscal, monetary and exchange rate policies to fight inflation in Brazil, empirically investigating whether monetary policy has really the greatest impact on inflation in the long run. For it, it was estimated a Vector Error Correction model (VEC). According to the results, the main variables that affect inflation in the long run are the internal public debt and monetary agerado (M4). It is also high the sensitivity-exchange of the inflation.The IPCA showed little sensitivity in the long term changes in the Selic rate. Although it presents itself as the main policy instrument in guiding the regime of inflation targets, changes in the interest rate have not been decisive in long-term inflation control.
\end{abstract}

Keywords: Sensitivity. Inflation. Political. Brazil. 


\section{INTRODUÇÃO}

Existe o consenso de que reduzidos níveis de inflação são pré-condição para a sustentabilidade do crescimento econômico. Para Araújo e Modenese (2010), a estabilidade de preços é promotora do bem-estar social e deve ser perseguida. $\mathrm{O}$ fato de o País ter experimentado um longo período de alta inflação crônica contribuiu para a aceitação, quase que incondicional, dessa concepção por boa parte da academia e dos formadores de opinião.

Bernanke et al. (1999) destacam que a inflação compromete a eficiência econômica, mostrando-se prejudicial ao crescimento econômico. Para o autor, a estabilidade de preços écondição necessária para que o sistema econômico funcione eficientemente, contribuindo para a consecução dos demais objetivos macroeconômicos. Essa é uma das principais razões para a adoção do Regime de Metas da Inflação (RMI), que se justificaria, também, porque: a meta de inflação atua como uma âncora nominal e a moeda é neutra em longo prazo. Mesmo taxas moderadas de inflação são prejudiciais ao crescimento e à eficiência econômica, e a manutenção da inflação em níveis baixos e estáveis é importante e, talvez, necessária para atingir outros objetivos macroeconômicos.

No Brasil, pode-se discutir que o combate à inflação tem sido prioridade de política econômica, pelo menos, desde 1994 com o Plano Real, que se constituiu em um dos mais relevantes eventos da história econômica brasileira contemporânea, ao ter encerrado a sucessão de cinco tentativas de combate à inflação: Bresser (1987), Collor I (1990), Collor II (1991), Plano Cruzado (1986) e Verão (1989).

Outra evidência da prioridade das políticas econômicas brasileiras no combate à inflação é a adoção do RMI, uma estratégia de condução de política monetária marcada pelo compromisso institucional da autoridade monetária em adotar a estabilidade de preços como a principal meta de política monetária - à qual se subordinam os demais objetivos macroeconômicos, inclusive o crescimento econômico.

O sistema de metas de inflação foi implementado no Brasil em 1999 para ser a nova âncora nominal da economia, em substituição à taxa de câmbio. Na maioria das vezes visto como uma política eficiente, por manter a inflação sob controle, o RMI tem apresentado problemas relacionados ao alcance de seus objetivos e, sobretudo, aos elevados custos sociais e de desenvolvimento econômico.

A atual forma de condução da política monetária brasileira tem como principal objetivo o controle inflacionário. A taxa de juros é o principal instrumento utilizado pelo Banco Central para estabilizar a inflação em longo prazo, sendo admitido o 
seu impacto sobre a demanda agregada em curto prazo. Entretanto, em longo prazo, as variáveis reais são afetadas apenas pelo lado da oferta, como, por exemplo, no caso de flexibilidade no mercado de trabalho (NEVES; OUREIRO, 2008).

Diversos estudiosos têm buscado debater e investigar a ineficácia da política monetária no combate à inflação, entre eles, Araújo e Modenesi (2010), Bresser-Pereira e Silva (2009), Favero e Giavazzi (2002), Figueiredo e Ferreira (2002) e Holland (2006) argumentam que aumentos na taxa Selic não seriam a forma mais eficaz de combate à inflação.

Segundo Araújo e Modenese (2010), a política monetária tem sido pouco eficaz, e o combate à inflação tem resultado em elevada taxa de sacrifício. É baixa a sensibilidade-juros da inflação: uma elevação da Selic tem impacto reduzido sobre a taxa de variação do IPCA. Concomitantemente, uma ampliação da taxa de juros desaquece a economia, valoriza a moeda doméstica e aumenta o estoque de dívida pública. Portanto, o balanço entre os custos e os benefícios da política monetária é, claramente, desfavorável.

Os autores Bacha (1994), Lopreato (2002), Martone (2007), Oreiro e Paula (2010) e Pastore e Pinotti (2006) atribuem maior impacto da política fiscal sobre a inflação. Segundo tal concepção, os elevados déficits do governo são a principal razão para as pressões inflacionárias e consequentes altas da taxa de juros.

Em outros trabalhos, trata-se o câmbio como o principal condicionante da eficácia do RMI. Para Barbosa Filho (2007) e Bresser-Pereira e Silva (2009), a contenção do nível de preços ocorre por elevações na taxa de câmbio nominal pelo diferencial de juros.

Nesse contexto, em meio às colocações acerca do RMI, suas vantagens e ineficiências, no presente trabalho buscou-se investigar empiricamente quais políticas têm maior impacto no controle da inflação em longo prazo. Com tais resultados, comprovar-se-á se o atual regime monetário do País é eficaz no combate à inflação via alterações na taxa de juros.

O objetivo principal neste estudo foi analisar a sensibilidade das políticas monetária, fiscal e cambial no combate à inflação no Brasil.

Na seção 2, são brevemente levantados os problemas relacionados à inflação e é apresentado o RMI e suas principais características, pontos fortes e ineficiências. Nas subseções, são apresentados debates sobre a política monetária, fiscal e cambial no combate à inflação. 
Na seção 3, são relacionados os procedimentos metodológicos e é apresentado um modelo de Vetores de Correção de Erros (VEC) para avaliação da sensibilidade da inflação às políticas econômicas.

Na seção 4, são apresentados os resultados do trabalho, os impactos das variáveis e são analisadas no Índice de Preços ao Consumidor Amplo (IPCA) em longo prazo. As conclusões são apresentadas na última seção.

\section{REFERENCIAL TEÓRICO}

\subsection{A INFLAÇÃO E O REGIME DE METAS DA INFLAÇÃO (RMI)}

É amplamente difundida na sociedade brasileira a crença de que reduzidos níveis de inflação são pré-condição para a sustentabilidade do crescimento econômico. De acordo com essa ideia, a estabilidade de preços é absolutamente prioritária e deve, então, ser perseguida.

A identificação dos custos da inflação - bem como dos canais por meio dos quais a inflação reduz o nível de utilidade dos agentes econômicos e, portanto, de bem-estar social - é, historicamente, tema recorrente. A inflação acarreta distorções, principalmente, sobre distribuição de renda, expectativas empresariais, mercado e capitais e balanço de pagamentos.

Os defensores do RMI ressaltam que economias com elevadas taxas de inflação apresentam os seguintes problemas:

a) superdimensionamento do sistema financeiro;

b) suscetibilidade a crises financeiras - considerando-se a maior fragilidade de seu sistema financeiro em relação às economias que têm preços estáveis;

c) deterioração do sistema de impostos;

d) ocorrência de efeitos distributivos, pois os mecanismos de indexação não protegem perfeitamente os rendimentos dos diferentes grupos econômicos;

e) custos de menu ou de remarcação de preços;

f) mau funcionamento dos mercados e alocação ineficiente de recursos em face de uma sinalização imperfeita realizada pelo sistema de preços -, o que diminui a produtividade dos fatores de produção e, portanto, compromete o crescimento econômico (INSTITUTO DE PESQUISA ECONÔMICA APLICADA, 2010). 
O RMI é uma estratégia de condução da política monetária marcada pelo compromisso institucional da autoridade monetária em adotar a estabilidade de preços como a principal meta da política monetária - à qual se subordinam os demais objetivos macroeconômicos, inclusive o crescimento econômico (INSTITUTO DE PESQUISA ECONÔMICA APLICADA, 2010).

Atualmente, uma série de países apresenta como opção de regime monetário a estratégia de metas para a inflação. Sob esse regime, a forma de conduzir a política monetária, se por meio de alterações mais abruptas ou mais suaves da taxa básica de juros, encontra-se fortemente relacionada aos resultados observados para os desvios da inflação em relação à meta, para o hiato do produto, para as expectativas formadas para a inflação, em alguns casos, para o comportamento da taxa de câmbio e, também, à credibilidade da própria estratégia de metas de inflação (MONTES; BASTOS, 2011).

A implantação do RMI se consubstancia em: a) anúncio de uma meta para a inflação; b) a utilização da taxa básica de juros como instrumento de combate à inflação, e não o controle da quantidade ofertada de moeda ou do nível de taxa de câmbio; c) maior transparência na condução da política monetária, materializada em um esforço de aprimoramento dos canais de comunicação entre o Banco Central (BC) e os agentes econômicos, o que possibilita o monitoramento e a avaliação do desempenho da autoridade monetária; d) autonomia de instrumentos por parte do BC - isto é, liberdade para determinar a trajetória dos instrumentos de política monetária, essencialmente a taxa de juros (INSTITUTO DE PESQUISA ECONÔMICA APLICADA, 2010).

Para Serrano (2010), a visão consensual do regime de metas de inflação pode ser sintetizada em três proposições: o núcleo ou tendência da inflação é resultado de choques de demanda, a taxa de juros é operada com o objetivo de controlar a demanda agregada e alguma variação na taxa de câmbio ocorre como um efeito colateral das mudanças na taxa de juros.

O mesmo autor questiona: como é possível controlar a inflação a partir da taxa de juros, em uma economia em que não há evidência de que o controle da demanda agregada seja capaz de conter diretamente o aumento de preços ou salários nominais, e na qual há um conjunto de pressões inflacionárias pelo lado dos custos? A resposta é que, na prática, o sistema funciona da seguinte maneira: aumentos da taxa de juros valorizam a taxa de câmbio nominal; as mudanças na taxa de câmbio, por sua vez, com alguma defasagem, têm um forte impacto de custos, diretos e indiretos, sobre todos os preços da economia, inclusive os "livres". 
Portanto, a operação concreta do sistema de metas inflacionárias no Brasil tem as seguintes características: o núcleo da inflação é de custos, as variações na taxa de juros afetam a taxa de câmbio, as variações no câmbio afetam os custos e, depois, os preços de todos os setores da economia. O primeiro impacto ocorre nos preços dos transacionáveis e dos monitorados e, posteriormente, o impacto dos preços por atacado afeta os custos e os índices de preços "livres” e dos não transacionáveis; o efeito dos juros na demanda agregada é, afinal, apenas um efeito colateral da política monetária, e a âncora do sistema é a baixa resistência dos salários reais médios.

Mishkin (2000) sumariza as desvantagens do regime de metas de inflação apontadas por muitos autores. Segundo o autor, a meta de inflação é muito rígida, e isso permite um nível de discricionariedade que compromete a estabilidade do produto e o crescimento econômico. Além disso, a defasagem de tempo entre a adoção da política monetária, seu efeito sobre a inflação e a dificuldade de controlá-la podem produzir um banco central responsavelmente fraco.

Soma-se a esses problemas o fato de que a necessidade de o câmbio ser flexível no regime de metas de inflação pode causar instabilidade financeira perante possíveis ataques especulativos. Por fim, o regime de metas de inflação não pode evitar a ocorrência da dominância fiscal. Diante da existência de elevados déficits fiscais, a monetização da dívida pública pode ocorrer e, com isso, promover a aceleração inflacionária (NEVES; OUREIRO, 2008).

Para Bresser-Pereira e Silva (2009), o balanço entre os custos e benefícios do atual regime de política monetária suscita dúvidas. Nesse sentido, trata-se de uma estratégia de estabilização que pode estar comprometendo o desenvolvimento do País. O que mais chama a atenção é a baixa sensibilidade da inflação à taxa de juros. Ou seja, uma elevação da taxa Selic tem reduzido impacto de desinflação. Essa constatação é séria, pois, no RMI, a taxa de juros é o principal instrumento de combate à inflação.

Como a taxa Selic é pouco potente para conter os preços, o BCB precisa mantê-la em níveis excessivamente elevados para que as metas de inflação sejam cumpridas. Dessa forma, o ganho de bem-estar em termos de uma redução da inflação - decorrente de um regime de elevadas taxas de juros - mostra-se pequeno. Já o efeito de um aumento da taxa Selic sobre o nível de atividade é claramente negativo. Em resposta a um aumento nos juros, a economia se desacelera e o desemprego aumenta. Assim, a rigidez que marca a política monetária no País é uma das razões - ainda que não a única - para que o desempenho da economia brasileira esteja ainda abaixo do seu potencial (INSTITUTO DE PESQUISA ECONÔMICA APLICADA, 2010). 


\subsection{A POLÍTICA MONETÁRIA E A INFLAÇÃO}

Segundo Modenesi e Modenesi (2012), a política monetária brasileira constitui uma anomalia no cenário mundial. A taxa de juros real do País foi mais do que o dobro da média da América Latina (AL) e sistematicamente superior à média dos emergentes entre 1995 e 2008. O baixo grau de eficácia da política monetária tem sido indicado por muitos como causa da manutenção da Selic em níveis excessivamente elevados.

Com a consolidação do Plano Real e a implantação do RMI, em 1999, esperava-se que, à medida que ocorresse a estabilização dos preços, a Selic passasse a níveis de economias com preços estáveis. Entretanto, mesmo a despeito da inflexão das políticas cambial e fiscal, a partir de 1999, a taxa de juros não convergiu para um patamar comparativo às economias desenvolvidas.

A inflação vem se mantendo em patamares que podem ser considerados elevados, principalmente em relação à experiência internacional. No período de 1995 a 2010, o IPCA ficou abaixo de 5\% em apenas quatro anos, atingindo média próxima a 7\%. Apesar da longa manutenção da Selic em níveis elevados, a inflação tem cedido pouco (MODENESI; MODENESI, 2012).

Para Pastore (1995), a política monetária no Brasil tem eficácia reduzida no controle da demanda agregada de bens. A explicação mais utilizada é que a base monetária e o MI não são o agregado monetário mais importante, dado o elevado grau de substituição entre outros agregados, entre os quais a dívida pública. A liquidez dos títulos públicos, ou dos depósitos de indivíduos e empresas em instituições financeiras que tenham o lastro desses títulos, aproxima-se muito da liquidez da própria moeda.

Marques e Fochezatto (2006) apresentam evidência empírica favorável à existência de um canal de custos na condução da política monetária brasileira. Admitindo-se que os preços são determinados por uma regra de markup sobre os custos de produção, um aumento dos juros elevaria os custos, os quais, por sua vez, poderiam ser repassados para os preços. Nesse caso, o impacto inflacionário do aumento dos custos de produção pode anular o efeito depressivo sobre os preços resultante de uma contração monetária.

Outro fator a comprometer a eficácia da política monetária é a elevada participação dos preços administrados no IPCA (cerca de 30\%). A quase insensibilidade desses preços aos juros, aliada ao fato de que sua taxa de crescimento, muitas vezes, tem sido superior à inflação livre - requer que os preços livres sejam excessivamente represados, para compensar a forte pressão (direta e indireta) exercida pelos 
administrados sobre o IPCA, como ocorrido entre 1999 e 2006. Assim, a política monetária torna-se menos eficaz: a Selic deveria ser fixada em níveis elevados para manter a demanda agregada suficientemente reprimida de forma que seja possível o cumprimento da meta de inflação. Ou seja, para uma dada meta, a existência de preços administrados implica que a Selic deve ser mantida em nível superior àquele que seria necessário, caso todos os preços fossem livres (FIGUEIREDO; FERREIRA, 2002).

De acordo com Bresser-Pereira e Silva (2009), o Brasil vem enfrentando a armadilha taxa de juros/câmbio desde a implementação do Plano Real. Sempre que o Banco Central inicia um processo de redução da taxa de juros, há uma depreciação cambial, e as consequentes alterações nos preços vindas do lado da oferta provocam aumento da inflação. As autoridades reagem com um novo aumento da taxa de juros. Com isso, uma inflação advinda da oferta é combatida com uma política de contração de demanda. Sempre que a taxa de juros é reduzida e há um sinal de crescimento econômico, o governo tenta evitar a depreciação cambial elevando a taxa Selic e, consequentemente, aumentando o desemprego. A armadilha coloca a economia do País em um círculo vicioso de curto prazo.

Araújo e Modenesi (2010) mostram que é baixa a sensibilidade da inflação à taxa de juros. Pela estimação de um Modelo de Vetores Autorregressivos (VAR), concluem que um aumento da Selic tem reduzido impacto deflacionário. Assim, o Banco Central do Brasil (BCB) precisaria mantê-la em níveis demasiadamente elevados para que as metas de inflação sejam minimamente cumpridas. Já o efeito de uma elevação da Selic sobre o nível de atividade é, claramente, negativo: a economia se desacelera. Os autores identificam problema no mecanismo de transmissão: um aumento dos juros contrai a demanda agregada; porém, o desaquecimento da economia não se transmite integralmente para os preços. Isto é, o arrefecimento da inflação é desproporcionalmente inferior à queda da atividade.

Além disso, a importância da taxa de câmbio no mecanismo de transmissão da política monetária torna indesejável a adoção de mecanismos de controle à entrada de capitais. A valorização cambial é a essência da atual política de estabilização. Desse modo, a adoção de medidas de controle à entrada de capitais é incompatível com a política monetária em curso.

Favero e Giavazzi (2002) e Holland (2006) consideram que o fato de o BCB não possuir independência formal prejudicaria o funcionamento do canal das expectativas na transmissão da política monetária. Assim, esta perderia credibilidade, comprometendo sua capacidade de coordenar as expectativas de inflação, o que tornaria necessária a fixação da Selic em níveis relativamente elevados. 


\subsection{A POLÍTICA FISCAL E A INFLAÇÃO}

Dornbush (1998) está entre os precursores da concepção de que a gestão da dívida pública pode comprometer a eficácia da política monetária. Ele propõe que o estoque e, notadamente, a estrutura da dívida podem tornar o consumo uma função positiva da taxa de juros. Caso o público retenha parcela substancial de dívida de curta maturação, uma elevação dos juros gera um incremento de renda que, por sua vez, pode se traduzir em aumento da demanda agregada. Nesse caso, compromete-se a eficácia da política monetária no combate à inflação.

Segundo Lopreato (2002), o combate ao processo inflacionário tem de ser feito por meio de um programa de estabilização cujo núcleo é o controle do déficit público. Essa meta pode ser alcançada com a reforma fiscal e o compromisso do Banco Central de não monetizar o déficit do setor público. O foco central da política econômica, portanto, é o combate ao déficit público e o controle do financiamento monetário responsável pela aceleração inflacionária, criando as condições para conter a inflação.

Para Barbosa (2006), o efeito contágio entre a dívida e a política monetária explicaria a manutenção da Selic em patamares elevados. Vários autores, entre eles Delfim Netto (2005), Martone (2007) e Oreiro e Paula (2010), consideram que a fragilidade das contas públicas explicaria o excesso de rigidez da política monetária. Os adeptos dessa tese sustentam que zerar (ou pelo menos diminuir) o déficit nominal do setor público seria uma pré-condição fundamental para a redução da taxa básica de juros.

A visão fiscalista também sustenta que a Selic é elevada por um problema de falta de coordenação entre as políticas fiscal e monetária. A política fiscal é considerada demasiadamente expansionista, o que inflaria a demanda agregada e, assim, pressionaria a inflação. Dado o compromisso com a estabilidade de preços, caberia à política monetária o papel de anular o efeito expansionista da política fiscal. Nesse sentido, trata-se de uma aplicação do conceito de efeito deslocamento: uma expansão dos gastos públicos resultaria em elevação dos juros para desestimular o investimento privado. Pode-se dizer que essa concepção deriva, em última instância, da visão ortodoxa segundo a qual a inflação é, essencialmente, um problema fiscal (PASTORE; PINOTTI, 2006).

Para os mesmos autores, a crença de que o excesso de endividamento e/ou de gastos públicos é responsável pelas altas taxas de juros não deve ser confundida com a tese da baixa eficácia da política monetária. De acordo com esta, a rigidez monetária decorreria de falhas circunscritas aos canais de transmissão da política monetária, independentemente da instância fiscal. Para a concepção fiscalista, mesmo resolvidos 
todos os problemas que comprometeriam a transmissão, a Selic ainda deveria permanecer elevada - seja porque a dívida pública é alta, seja porque o mix monetário-fiscal não é adequado. Ou seja, a flexibilidade, ou até mesmo a leniência fiscal, é considerada a causa da rigidez monetária.

\subsection{A POLÍTICA CAMBIAL E INFLAÇÃO}

A inflação de custos tende a se reduzir quando a de câmbio se reduz em resposta a um aumento na taxa Selic. O excesso de rigidez na política monetária - ao criar um elevado diferencial entre a taxa de juros doméstica e a externa - é um dos fatores a contribuir para o expressivo processo de valorização do real, verificado a partir de 2003 (INSTITUTO DE PESQUISA ECONÔMICA APLICADA, 2010).

É a valorização do câmbio resultante do elevado diferencial de juros que torna possível a transformação de grandes choques de oferta negativos em dólares em choques de oferta positivos em reais. Outro fator de controle da inflação de custos tem sido a política do governo de não repassar integralmente para os preços internos da gasolina e, especialmente, do óleo diesel, as brutais variações externas do preço do petróleo.

Para Bresser-Pereira e Silva (2009), alguns autores têm creditado à política de metas de inflação resultados que não lhe são devidos. As principais causas dos baixos índices inflacionários são decorrentes da valorização cambial. Os países que adotaram o regime de metas não conseguiram resultados melhores nem piores do que os que não adotaram o sistema.

Segundo Barbosa Filho (2007), em todos os anos que a inflação ficou dentro da faixa estipulada como meta (fora o ano 1999, que marca a transição para o sistema), o câmbio nominal se valorizou. O grande diferencial de juros e a contínua valorização nominal do real manteve a inflação dentro da meta, apesar do forte crescimento dos preços internacionais das commodities e do petróleo em dólares.

\section{PROCEDIMENTOS METODOLÓGICOS}

\subsection{SÉRIES DE DADOS}

As séries de dados utilizadas no trabalho se iniciam em janeiro de 1999, data da liberalização cambial que significa a perda da âncora cambial. Ao todo foram 174 observações mensais, o que passa confiabilidade aos resultados encontrados.

As variáveis utilizadas são: JUROS - são a taxa Selic efetiva overnight; IPCA - Índice de Preços ao Consumidor Amplo, encadeado em dezembro de 1993; CN - taxa de câmbio nominal em R\$/US\$; DIV - dívida total do setor público; NFSP - necessi- 
dade de financiamento do setor público, conceito primário sem desvalorização cambial acumulado em 12 meses como porcentagem do PIB; e M4 - agregado monetário.

As séries dos JUROS, CN, DIV, M4 e NFSP foram obtidas com o BCB. O IPCA utilizado é fornecido pelo Instituo Brasileiro de Geografia e Estatística (IBGE). Todos os dados estão disponíveis no site do Instituto de Pesquisas Econômicas Aplicadas (IPEA).

\subsection{MODELO DE VETORES CORREÇÃO DE ERROS (VEC)}

Com o intuito de avaliar a sensibilidade das políticas econômicas no combate à inflação, foi estimado um modelo de Vetores de Correção de Erros (VEC). Primeiramente, foram realizados os testes de integração ADF e DF - GLS e, para as séries em estudo, não foi possível rejeitar a hipótese nula de que as séries possuem uma raiz unitária, sendo, portanto, séries I (1).

Para determinar a ocorrência de cointegração entre as séries de dados, utilizou-se o procedimento de Johansen (1988). De acordo com Engle e Granger (1987), o teste de cointegração parte da intuição de que duas ou mais variáveis, ditas integradas de primeira ordem, ou seja, I (1) - ou, ainda, em termos mais formais: variáveis não estacionárias, com presença de tendência estocástica - não podem ser regredidas, pois tal procedimento pode produzir uma regressão espúria. Uma regressão espúria é aquela desprovida de significado econômico, um problema que tende a acontecer quando as variáveis em análise apresentam uma tendência estocástica e não uma tendência determinística. Para um tratamento formal do problema da regressão espúria, ver Granger e Newbold (1974). Suponha, entretanto, uma combinação linear entre essas variáveis. Se essa combinação linear for um processo estocástico estacionário com média zero, pode-se dizer que essas variáveis cointegram e possuem, portanto, uma relação de longo prazo de equilíbrio.

Diferentemente do método de Engle e Granger (1987), o procedimento de Johansen utiliza a Máxima Verossimilhança para estimar a presença de vários vetores e não de um único vetor de cointegração. Além disso, pode-se realizar testes sobre a significância dos parâmetros que compõem os vetores de cointegração, o que será fundamental para se estabelecer o grau de integração entre eles.

Por meio do método de Johansen, estima-se a matriz de coeficientes do modelo estrutural, que representa a relação de longo prazo entre as variáveis investigadas, conforme a Equação 1. 


$$
\Delta X_{t}=\Pi X_{t-1}+\sum_{i=1}^{p-1} \Lambda_{i} \Delta X_{t-1}+\delta^{\prime} d_{t}+e_{t}
$$

Sendo que é o vetor que reúne as observações referentes ao Índice Nacional de Preços ao Consumidor Amplo, a taxa de câmbio nominal, o agregado monetário (M4), a dívida pública (DIV) e a necessidade de financiamento do setor público (NFSP) (resultado primário do governo central) no tempo $t$ em termos de seus logaritmos naturais, é o vetor de parâmetros a serem estimados, e é o vetor multivariado dos termos de erro, que por hipótese são não correlacionados. E, ainda, tem-se que:é um vetor com variáveis determinísticas e que poderia incluir também dummies sazonais ou outras variáveis determinísticas;é uma matriz de coeficientes, cuja dimensão é compatível com $d_{t}$.

Na análise da cointegração, o fator central é o posto de , que é igual ao número de vetores cointegrantes independentes. A matriz representa a matriz de respostas de longo prazo, cujo posto é essencial para se obterem informações sobre a ordem de integração do sistema. Se o posto da matriz é pleno $(r=n)$, a solução de longo prazo é dada por $n$ equações independentes; em outras palavras, as $n$ variáveis do sistema são restritas por $n$ restrições de longo prazo, nesse caso, cada variável deve ser estacionária. Se o posto de é reduzido $(r<n)$, existem $r$ vetores de cointegração e $n-r$ tendências estocásticas no sistema.

O teste utilizado para verificar o número de parâmetros que sejam estatisticamente diferentes de zero teve as suas distribuições assintóticas derivadas por Johansen (1988) e Johansen e Juselius (1990), com uma delas convergindo para o traço da matriz e a outra para o autovalor máximo da matriz. A estatística do traço testa a hipótese nula de existência de no máximo $k$ vetores cointegrantes contra a alternativa de que o número desses vetores é maior do que $k$, sendo determinada pela Equação 2.

$$
\lambda_{\text {traço }}(k)=-T \sum_{i=k+1}^{N} \ln \left(1-\lambda_{i}\right) .
$$

Para checar a hipótese nula de existência de exatamente $k$ vetores cointegrantes contra a alternativa de que o número desses vetores é igual a $k+1$, utilizou-se a estatística de autovalor máximo, fornecida pela Equação 3: 


$$
\lambda_{\text {max }}(k, k+1)=-T \ln \left(1-\lambda_{k+1}\right) .
$$

Com esses testes, Johansen (1988) e Johansen e Juselius (1990) estabeleceram os testes estatísticos visando descobrir o número de relações de cointegração entre as variáveis. O primeiro passo é investigar o número de vetores de cointegração. No presente trabalho, encontrou-se a evidência de que as séries se cointegram, possuindo apenas um vetor de cointegração.

\section{RESULTADOS}

É preciso determinar cuidadosamente o modelo de cointegração a ser testado e a ordem de defasagem dos componentes. O problema maior é determinar qual modelo de cointegração utilizar. As possibilidades relacionam-se à existência de constante e tendência no nível do vetor (no presente caso:) e no vetor de cointegração. A partir da definição de qual deles cabe usar, definem-se os valores críticos a consultar (BUENO, 2008).

O modelo de cointegração a ser testado neste trabalho, considerando-se a Equação (1) seria na forma de permitir uma constante dentro e fora do espaço de cointegração (constante irrestrita).

É necessária a readequação da Equação (1), considerando a hipótese de posto reduzido, ou seja, rank. Sob essa hipótese, pode ser escrita como o produto de duas matrizes, . Tem-se, portanto a Equação 4.

$$
\Delta X_{t}=\alpha\left\{\beta^{\prime}\left[X_{t-1}+\mu_{0}\right]\right\}+\delta_{0}+\sum_{i=1}^{p-1} \Lambda_{i} \Delta X_{t-i}+e_{t}
$$

Como já mencionado, quando as variáveis são cointegradas, a regressão entre elas pode ser expressa com um modelo de correção de erros. Portanto, o Vetor de Correção de Erros (VEC) irrestrito foi modelado com a variável dependente fornecidada por (sendo ), com defasagens de primeira ordem (para se manter coerente com a análise VAR, em que o termo em nível, sem a primeira diferença, era de segunda ordem), e os termos deterministas compreendendo uma constante irrestrita (dentro e fora do espaço de cointegração). O VEC foi estimado segundo a Equação (4), apresentada anteriormente. Na tabela 1 apresentam-se os resultados do Vetor de Correção de Erros. 
Tabela 1 - Modelo VEC estimado (solução de longo prazo)

\begin{tabular}{lrr}
\hline Variáveis Y= IPCA & Coeficientes $\beta$ & Estatística t \\
\hline LNJUROS(-1)* & -0.043319 & {$[2.09386]$} \\
LNDIV(-1)* & +0.262502 & {$[-5.41782]$} \\
LNCAMBIO(-1)* & +0.145384 & {$[-6.23579]$} \\
LNM4(-1)* & +0.248635 & {$[-7.90037]$} \\
NFSP2(-1)* & -0.019861 & {$[$ 3.04593] } \\
C & +0.505428 & \\
\hline
\end{tabular}

Fonte: os autores.

Nota: $\left(^{*}\right)$ variáveis significativas.

Na Tabela 1 são apresentados os coeficientes do modelo de Vetores Correção de Erros (VEC).

Todas as variáveis se mostraram significativas para a análise da sensibilidade no combate à inflação, apresentando relação de longo prazo com o IPCA. Os resultados da Tabela 1 mostram que todos os sinais das variáveis investigadas se apresentam de acordo com a perspectiva teórica, a não ser a NFSP.

A variável que apresenta maior impacto no IPCA em longo prazo é a dívida do setor público (DIV). Aumentos de 1\% na dívida pública acarretam elevação em 0,26\% na inflação. Tais resultados mostram o grande impacto de longo prazo da política fiscal na inflação e corroboram os argumentos de autores que consideram que o combate ao processo inflacionário tem de ser feito por meio de um programa de estabilização cujo núcleo é o controle do déficit público.

Para Franco (2006), Lopreato (2002), Pastore (1995) e Pastore e Pinotti (2006), a política fiscal brasileira é excessivamente expansionista, o que estimula a demanda agregada e a inflação. Isso se torna um problema quando a expansão dos gastos resulta em aumento dos juros para desestimular o investimento privado. Para os defensores dessa tese, a diminuição do déficit nominal do setor público seria uma pré-condição fundamental para a redução da taxa básica de juros, mantendo baixos níveis inflacionários. Barbosa (2006), Delfim Netto (2005), Martone (2007) e Oreiro e Paula (2010) corroboram que o efeito contágio da dívida seria a principal razão para as pressões inflacionárias.

A segunda variável com maior impacto na inflação é o agregado monetário (M4). Aumentos da ordem de 1\% no agregado monetário elevam a inflação em 0,24\%. Alguns pesquisadores, entre eles Dornbush (1998) e Pastore (1995), defendem que a base monetária e o MI não são o agregado monetário mais importante, dado o 
elevado grau de substituição entre outros agregados, entre os quais, a dívida pública. A alta liquidez do agregado monetário se aproxima muito da liquidez da própria moeda. Ademais, tais ativos podem ser convertidos em moeda de baixo risco, ou com uma probabilidade extremamente baixa de ganhos ou de perdas de capital. Portanto, elevações no M4 acarretam processos inflacionários em longo prazo.

O câmbio nominal (CN) também tem um impacto significativo na inflação. Uma elevação (ou uma desvalorização cambial) de ordem de 1\% no câmbio faz com que a inflação aumente em 0,14\%. Tal resultado condiz com as teses de Barbosa Filho (2007), Bresser-Pereira e Silva (2009) e Serrano (2010), que enfatizam que as principais causas dos baixos índices inflacionários do Brasil são decorrentes da valorização da moeda nacional perante o dólar. Para os autores citados, o grande diferencial da taxa de juros e a contínua valorização nominal do real têm mantido a inflação dentro da meta, apesar da elevação dos preços internacionais das commodities e do petróleo, em dólares. Os resultados aqui encontrados validam que o câmbio apreciado tem contribuído para que as metas inflacionárias sejam atingidas desde a liberalização cambial.

O modelo mostra que a taxa Selic (JUROS) tem um impacto muito pequeno no nível de preços. Aumentos de $1 \%$ na taxa de juros provocam diminuições inferiores a $0,05 \%$ na inflação. Tal resultado responde uma questão central do presente trabalho, sobre a ineficiência da atual política monetária, e reforça o posicionamento de estudiosos que consideram que a taxa de juros não é eficaz no controle da inflação. Araújo e Modenesi (2010) comprovaram a baixa sensibilidade da inflação à taxa de juros por meio de um modelo VAR. Para Figueiredo e Ferreira (2002), a grande participação dos preços administrados no IPCA contribui com a ineficácia da taxa de juros no combate à inflação. Para Bresser-Pereira e Silva (2009), sempre que o Banco Central reduz a taxa de juros, há uma depreciação cambial e aumento nos preços vindos do lado da oferta. Reage-se com nova elevação da taxa de juros, combatendo-se uma inflação de oferta com uma política de contração de demanda.

Mesmo sendo significativa, a necessidade de financiamento do setor público (NFSP) foi a variável de menor impacto na determinação da inflação. Porém, os resultados encontrados não são condizentes com a base teórica a respeito do tema. Aumentos de $1 \%$ na necessidade de financiamento do setor público diminuem a inflação em 0,019\%. Torna-se necessária, portanto, uma investigação mais pormenorizada de tal variável para maiores inferências. 


\section{CONCLUSÃO}

De acordo com o modelo VEC estimado, as principais variáveis que impactam o IPCA em longo prazo são a dívida interna do setor público (DIV) e o agregado monetário (M4). Uma possível explicação seria que a expansão dos gastos do Governo resulta em aumento dos juros para desestimular o investimento privado, isso faz com que o agregado monetário aumente e ocorram pressões inflacionárias. Portanto, o combate à inflação perpassa pela estabilização do déficit público.

Como verificado em outros trabalhos, também é alta a sensibilidade-câmbio da inflação. O atingimento das metas da inflação ocorreu desde 1999, em grande parte pela apreciação do real perante o dólar. Nesse sentido, mesmo com o aumento dos preços das matérias-primas no mercado internacional, as metas inflacionárias foram atingidas em quase todos os anos.

O IPCA se mostrou pouco sensível em longo prazo a alterações na taxa Selic. Tal constatação valida a hipótese da baixa eficácia da taxa de juros no combate à inflação. Portanto, a principal conclusão deste artigo é que, apesar de se apresentar como o principal instrumento na condução do regime de metas da inflação, a política monetária via alteração na taxa de juros não tem sido determinante em longo prazo no controle inflacionário. Por outro lado, é alta a sensibilidade das políticas fiscal e cambial no combate à inflação.

O alto custo de cunho social e de desenvolvimento do regime de metas e sua baixa eficácia mostram que o cerne da política econômica brasileira apresenta limitações a serem debatidas.

\section{REFERÊNCIAS}

ARAÚJO, E.; MODENESI, A. M. Custos e benefícios do controle inflacionário no Brasil (2000-2008): uma análise empírica do mecanismo de transmissão da política monetária com base em um modelo VAR. In: ENCONTRO NACIONAL DE ECONOMIA, 28., 2010, Salvador. Anais... Salvador: ANPEC, 2010.

BACHA, E. L. O fisco e a inflação: uma interpretação do caso brasileiro. Revista de Economia Política, São Paulo, v. 14, n. 1, p. 53, jan./mar. 1994.

BARBOSA, F. H. The contagion effect of public debt on monetary policy: the Brazilian experience. Revista de Economia Política, São Paulo, v. 26, i. 2, p. 231-238, 2006. 
BARBOSA FILHO, N. Inflation targeting in Brazil: 1999-2006. 2007. Disponível em: <www.networkideas.org>. Acesso em: 23 jan. 2013.

BERNANKE, B. S. et al. Inflation targeting: lessons from the international experience. Princeton: Princeton University, 1999.

BRESSER-PEREIRA, L. C.; SILVA, C. G. O regime de metas de inflação no Brasil e a armadilha da taxa de juros/taxa de câmbio. In: OREIRO, J. L.; PAULA, L. F.; SOBREIRA, E. R. (Org.). Política monetária, bancos centrais e metas de inflação. Rio de Janeiro: FGV, 2009.

BUENO, R. L. S. Econometria de séries temporais. São Paulo: Cengage Learning, 2008.

DELFIM NETTO, A. Déficit nominal zero. Boletim de Conjuntura Economia \& Tecnologia, São Paulo, v. 2, p. 5-12, jul./ago. 2005.

DORNBUSH, R. Debt and monetary policy: the policy issues. In: CALVO, G.; KING, M. (Ed.). The debt burden and its consequences for monetary policy. London: Macmillan, 1998.

ENGLE, R. F.; GRANGER, C. W. J. Co-integration and error correction: representation, estimation and testing. Econometrica, Chicago, v. 55, i. 2, p. 251-276, 1987.

FAVERO, C. A.; GIAVAZZI, F. Why are Brazil's interest rates so high? Milano: IGIER, 2002. (Working Paper, 224).

FIGUEIREDO, F. M. R.; FERREIRA, T. P. Os preços administrados e a inflação no Brasil. Brasília: Banco Central do Brasil, 2002. (Trabalhos para Discussão, 59).

HOLLAND, M. Por que as taxas de juros de curto prazo são tão elevadas no Brasil? Economia \& Tecnologia, Curitiba, v. 4, p. 27-42, 2006.

INSTITUTO DE PESQUISA ECONÔMICA APLICADA. Macroeconomia para o desenvolvimento: crescimento, estabilidade e emprego. Rio de Janeiro, 2010. (Livro 4).

JOHANSEN, S.; JUSELIUS, K. Maximum likelihood estimation and inference on co-integration with applications to the demand for money. Oxford Bulletin of Economics and Statistics, Oxford, v. 52, i. 2, p. 169-210, 1990. 
JOHANSEN, S. Statistical analysis of co-integration vectors. Journal of Economic Dynamics and Control, St. Louis, v. 12, p. 231-254, 1988.

LOPREATO, F. L. C. Um olhar sobre a política fiscal recente. Economia e Sociedade, Campinas, v. 11, n. 2, p. 279-304, jul./dez. 2002.

MARTONE, C. Juros e ajuste fiscal: comentários. In: ROCCA, C. A. (Org.). Mercado de capitais, agenda de reformas e ajuste fiscal. Rio de Janeiro: Campus, 2007.

MISHKIN, F. S. Inflation targeting in emerging-market countries. Cambridge: National Bureau of Economic Research, 2000. (Working paper, 7618).

MODENESI, A. M.; MODENESI, R. L. Quinze anos de rigidez monetária no Brasil pós-Plano Real: uma agenda de pesquisa. Revista de Economia Política, São Paulo, v. 32, n. 3, jul./set. 2012.

MONTES, G. C.; BASTOS, J. C. A. Metas de inflação e estrutura a termo das taxas de juros no Brasil. Economia Aplicada, Ribeirão Preto, v. 15, n. 3, jul./set. 2011. Disponível em: <http://www.scielo.br/scielo.php?pid=S1413-80502011000300003\& script $=$ sci_arttext $>$. Acesso em: 23 jul. 2013.

NEVES, A. L.; OREIRO, J. L. O regime de metas de inflação: uma abordagem teórica. Ensaios FEE, Porto Alegre, v. 29, n. 1, p. 101-132, jun. 2008.

OREIRO, J. L.; PAULA, L. F. Por que a taxa de juros é tão alta? Valor Econômico, São Paulo, p. A-17, 05 nov. 2010.

PASTORE, A. C.; PINOTTI, M. C. Ajuste fiscal: o que diz o último capítulo? Valor Econômico, São Paulo, p. A-11, 24 abr. 2006.

PASTORE, A. C. Por que a política monetária perde eficácia? Revista Brasileira de Economia, Rio de Janeiro, v. 50, p. 281-311, 1995.

SERRANO, F. Juros, câmbio e o sistema de metas de inflação no Brasil. Revista de Economia Política, São Paulo, v. 30, n. 1, p. 63-72, jan./mar. 2010. 
Como citar este artigo:

\section{ABNT}

COSTA, Cassio Henrique; CAMPOS, Renato Silvério; CASTRO JÚNIOR, Luiz Gonzaga de. Sensibilidade das políticas monetária, fiscal e cambial no combate à inflação. RACE: Revista de Administração, Contabilidade e Economia, Joaçaba: Ed. Unoesc, v. 15, n. 1, p. 115-136, jan./abr. 2016. Disponível em: <http://editora. unoesc.edu.br/index.php/race>. Acesso em: dia/mês/ano.

APA

Costa, C. H., Campos, R. S., \& Castro Jr, L.G. de. (2016). Sensibilidade das políticas monetária, fiscal e cambial no combate à inflação. RACE: Revista de Administração, Contabilidade e Economia, 15(1), 115-136. Recuperado em dia/mês/ano, de http:// editora.unoesc.edu.br/index.php/race 
Anexo A - Estatísticas descritivas sugeridas das séries

\begin{tabular}{lll}
\hline Variáveis & Coeficientes â & Estatística t \\
\hline LNIPCA (-1) & 1.000000 & \\
LNJUROS (-1) & 0.043319 & {$[2.09386]$} \\
LNDIV (-1) & -0.262502 & {$[-5.41782]$} \\
LNCAMBIO (-1) & -0.145384 & {$[-6.23579]$} \\
LNM4 (-1) & -0.248635 & {$[-7.90037]$} \\
NFSP2 (-1) & 0.019861 & {$[3.04593]$} \\
C & -0.505428 & \\
\hline
\end{tabular}


